\title{
IMPACT OF CUTTING TOOL GEOMETRY ON THE DYNAMIC LOAD OF SYSTEM IN THE MACHINING PROCESS OF NICKEL ALLOY 625
}

\author{
Jiří Hajnyš', Tomáš Zlámal', Jana Petrů ${ }^{1}$, Marek Pagáč', Anna Rudawska² \\ 1 Faculty of Mechanical Engineering, VSB-Technical University of Ostrava, 17. Listopadu 2172/15 1, 70800 , \\ Ostrava, Czech Republic, e-mail: jiri.hajnys@vsb.cz, tomas.zlamal@vsb.cz, jana.petru@vsb.cz, marek.pagac@vsb.cz \\ 2 Faculty of Mechanical Engineering, Lublin University of Technology, Nadbystrzycka 36, 20-618 Lublin, Poland, \\ e-mail: a.rudawska@pollub.pl
}

Received: 2016.08.30

Accepted: 2016.10.08

Published: 2016.12.01

\begin{abstract}
The article is focussed on comparing and determining the impact of the cutting geometry of the cutting tool due to dynamic load on system and microgeometry machined surface. For longitudinal turning nickel alloy Alloy 625 (W. Nr. 2.4856) rounded indexable cutting insert was used (RCMT 10T3M0 - F2) and its equivalent squared indexable cutting insert (SNMG 120412 - MR3) coated with fine-grained PVD (Ti, Al) N + TiN. Experimental testing of nickel Alloy 625 was under predetermined cutting conditions. In the selected depth of the removed material of 0.5 $\mathrm{mm}$ and $1.5 \mathrm{~mm}$ was measured in the course of machining the size of the individual components of cutting forces.
\end{abstract}

Keywords: nickel Alloy 625, cutting geometry, cutting force.

\section{INTRODUCTION}

At present, the use of $\mathrm{Ni}$ superalloys has been constantly increasing and their application in many industries is already quite common. These materials are most commonly used for the manufacture of highly stressed components that are continuously exposed to adverse conditions. Thanks to their specific properties, such as creep resistance, heat resistance or increased resistance to chemical and oxidative effects, these materials are capable of withstanding high temperatures, pressures and severely corrosive environment. These and other characteristics which differentiate superalloys from conventional steels are determined by their chemical composition and microstructure. In terms of the machining of superalloys, it is their chemical composition and microstructure which are the main cause of decreased machinability, which is manifested by increased stress acting on the entire machining system and also worse economics of the manufacturing process. For most chip machining operations, super- alloys are among difficult-to-machine materials, which place increased demands on production technology $[1,9]$.

\section{ASPECTS OF THE MACHINING OF Ni SUPERALLOYS}

In terms of technical and economic aspects, efforts continue to be made to find a way to easily and efficiently machine superalloys. In the production of components made of these materials, it is especially necessary to observe the prescribed shape and dimensional accuracy, as well as high surface quality, which is often associated with the selected production technology. However, when selecting machining technology, it is necessary to take account of the undesirable properties of superalloys, such as high toughness, low thermal conductivity, surface hardening and abrasivity. Especially Ni-based superalloys are very prone to deformation hardening. This is due to the reinforcing phases of nickel, as well as the presence 
of very hard chromium carbides contained in the structure of the material. The intense deformation hardening occurs as a result of the action of force of the cutting tool on the layer being removed. The material is hardened in the primary and tertiary plastic deformation extending below the layer being removed. The material surface hardened in this manner together with the effects of very hard particles and low thermal conductivity creates a very aggressive environment for the tool edge, which causes rapid wear of the tool and shortens its life $[1,8,9]$.

A correctly chosen technology, cutting tool and cutting conditions are key to the effective treatment of $\mathrm{Ni}$ superalloys, subject to the requirements for dimensional and geometric precision of the manufactured components and the quality of surface finish. However, the quality of the machined surface often depends on the state of the cutting tool edge, which is interacting with the layer of the material being machined the entire time. The condition of the edge and its geometry affect the durability of the cutting tool, the process of forming a new surface, the shape of the chip being removed, micro-geometry of the machined surface, the direction and magnitude of the action of force, effects acting on the surface and subsurface, and friction and vibration in the machining process $[1,2,11]$.

\section{PROPOSED EXPERIMENTAL MACHINING OF ALLOY}

The experimental work was proposed to assess and determine the effect of geometry of the cutting tool on the course and magnitude of the dynamic load acting on the machining system. The test material selected for the machining was Alloy 625 (nickel alloy). This alloy has a high tendency to deformation hardening; therefore, it was necessary to choose appropriate cutting tool geometry in order to ensure that the action of force of the tool on the surface being created is minimised and appropriately distributed in various directions. The selection of the cutting tool geometry was also based on the requirements for resistance to wear, as well as efficient machining allowing higher feed rate, while complying with the required surface finish quality $[7,10,13]$.

The cutting tool selected for the machining of Alloy 625 was exchangeable cutting insert with a circular geometry and the designation RCMT
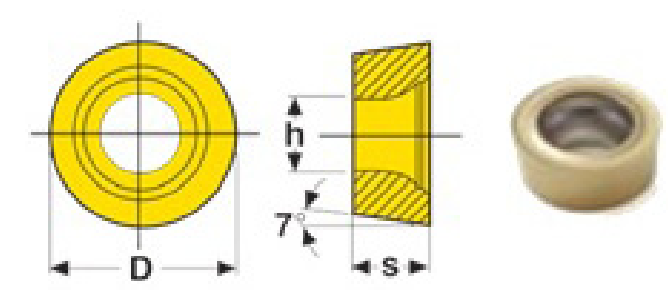

Fig. 1. Geometry of the cutting inserts used [5]

10T3M0 - F2, and a square plate with the designation SNMG 120412 - MR3, see Figure 1. These cutting inserts are coated with a thin layer of PVD coating (Ti, Al) $\mathrm{N}+$ TiN with a hard fine-grain structure suitable for the machining of Ni alloys. The geometry of cutting inserts was selected so as to ensure the relative strength of the cutting tool edge, wear resistance, stability of the cutting process, while also satisfying the requirements for quality and condition of the surface finish [5].

Two groups of cutting conditions were selected for the machining of the material by cutting inserts, see Table 1. During the experiment, the change of constant cutting speed $v_{c}$ and feed $f$ was accompanied only by a change in depth of cut $a_{p}$. Concerning cutting inserts with large tip radius or round cutting inserts, a change in the depth of the removed material layer was accompanied only by a change in the entering angle of the main edge $\kappa_{r}$, which affects the distribution and thus the magnitude of the individual components of cutting force $F$ during machining. The entering angle $\kappa_{r}$ was calculated for the selected depth of cut according to the formula as presented in Table $2[7,14]$.

The formula for the calculation of entering angle of the main cutting edge $\kappa_{r}$ depending on the depth of cut $a_{p}[7]$.

$$
\cos \kappa_{r}=\frac{\left(0.5 \cdot \mathrm{IC}-\mathrm{a}_{\mathrm{p}}\right)}{0.5 \cdot \mathrm{IC}}
$$

where:

$$
\begin{aligned}
& \text { IC }- \text { insert radius }[\mathrm{mm}] \\
& a_{p}-\text { depth of cut }[\mathrm{mm}]
\end{aligned}
$$

Table 1. Selection of cutting conditions

\begin{tabular}{|l|c|c|}
\hline \multicolumn{1}{|c|}{ Experimental measurement } & 1. TEST & 2. TEST \\
\hline Cutting speed $\mathrm{v}_{\mathrm{c}}\left[\mathrm{m} \cdot \mathrm{min}^{-1}\right]$ & 40 & 40 \\
\hline Feed $\mathrm{f}[\mathrm{mm}]$ & 0.3 & 0.3 \\
\hline Depth of cut $\mathrm{a}_{\mathrm{p}}[\mathrm{mm}]$ & 0.5 & 1.5 \\
\hline
\end{tabular}


Table 2. The values of the entering angle of the main edge $\kappa_{\mathrm{r}}$

\begin{tabular}{|c|c|c|}
\hline $\begin{array}{c}\text { Designation } \\
\text { according to - ISO }\end{array}$ & $\begin{array}{c}\text { Depth of cut } \\
\mathbf{a}_{\mathbf{p}}[\mathbf{m m}]\end{array}$ & $\begin{array}{c}\text { Entering angle } \\
\mathbf{k}_{\mathbf{r}}\left[^{\circ}\right]\end{array}$ \\
\hline RCMT 10T3M0 - F2 & 0.5 & 26 \\
\hline RCMT 10T3M0 - F2 & 1.5 & 45 \\
\hline SNMG 120412 - MR3 & 0.5 & 35 \\
\hline SNMG 120412 - MR3 & 1.5 & 45 \\
\hline
\end{tabular}

\section{COURSE OF EXPERIMENTAL MACHINING OF ALLOY 625}

Depending on the cut depth, during the experimental machining of Alloy 625 the authors evaluated the effect of the entering angle of the main cutting edge on the course and magnitude of the dynamic load acting on the machining system. An increase or decrease in cutting depth was accompanied by a change in the entering angle $\kappa_{r}$, see Figures 2 and 3. During the machining by a square cutting insert, $\kappa_{r}$ was $35^{\circ}$ at a cutting depth $a_{p}=0.5 \mathrm{~mm}$, because only the main edge tip radius $r_{\varepsilon}=1.2 \mathrm{~mm}$ was in contact with the material being machined. At $a_{p}=1.5 \mathrm{~mm}$, the angle was already $\kappa_{r}=45^{\circ}$. Concerning cutting inserts with a circular geometry, $\kappa_{r}$ varies along the entire length of the cutting edge, depending on the depth of the material being removed. At cutting depth $a_{p}=0.5 \mathrm{~mm}$, the value of angle was $\kappa_{r}=26^{\circ}$ and at $a_{p}=1.5 \mathrm{~mm}, \kappa_{r}=45^{\circ}$ was set to determine the effect of cutting inserts geometry and their comparison.

Changing the entering angle of the main cutting edge during machining was especially manifested by a changing distribution and magnitude of the cutting force components $F_{p}$ and $F_{f}$ and their resultant. During machining, the emphasis was primarily on the magnitude of the passive component of force acting in the radial direction due to mechanical loading of the surface layer of
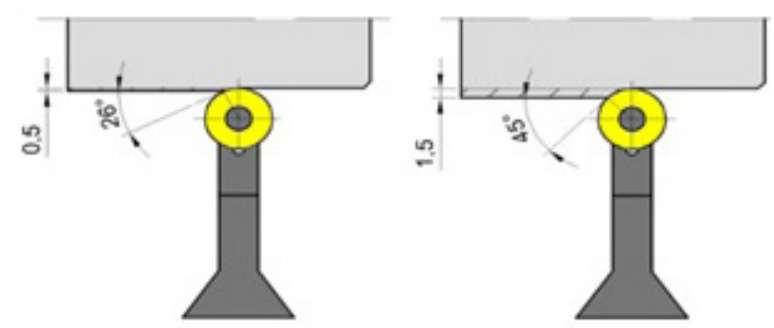

Fig. 2. Entering angle of the main edge of a circular cutting insert depending on cut depth

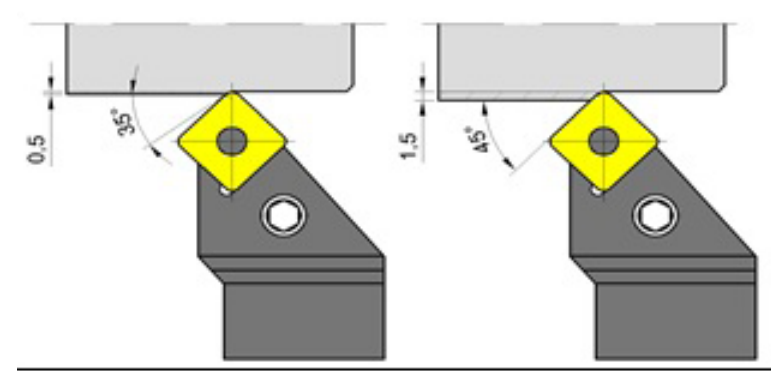

Fig. 3. Entering angle of the main edge of a square cutting insert depending on cut depth

the material being machined and its susceptibility to deformation hardening. The values of the entering angles of the main edge $\kappa_{r} \leq 45^{\circ}$ in the course of the experiment were chosen to avoid the formation of notch wear on the main flank of the tool and shortening its durability $[1,7,14]$.

\section{ASSESMENT OF FORCE CONDITIONS IN THE MACHINING PROCESS}

Knowledge of force conditions in the machining process allows the determination of mechanical stress acting on the entire technological machining system in terms of stiffness, strength and dynamic stability of the process. The resulting cutting force is given by the dynamic progress, and its instantaneous value fluctuates over time in the range of up to $20 \%$. During the experimental machining, cutting force and its components were determined by direct measurement in the machine - tool - workpiece system using a stationary piezoelectric Kistler 9129AA dynamometer [13].

To determine the effect of cutting geometry on the course and magnitude of the dynamic load of the system, a total of four measurements were carried out. When performing the measurement, the values of force load were recorded in the tangential, axial and radial directions, see Table 2 to 5 . From the measured values of $F_{c}, F_{f}$ and $F_{p}$ acting on the material being machined, the resulting cutting force $F$ was calculated [4].

The course of the machining of Alloy 625 under the given cutting conditions indicates that when using square and circular geometries of cutting inserts, very similar values were achieved. In both cases, the values of the passive component $F_{p}$ were greater than those of component $F_{f}$ It was mainly due to the geometry of the cutting inserts used (the adjusting angle of the main cutting edge $\kappa r$ and the tool tip radius $r_{\varepsilon}$ ). Such a tool ge- 
Table 3. The course of the force loading by a square cutting insert $\left(\mathrm{a}_{\mathrm{p}}=0.5 \mathrm{~mm}\right)$

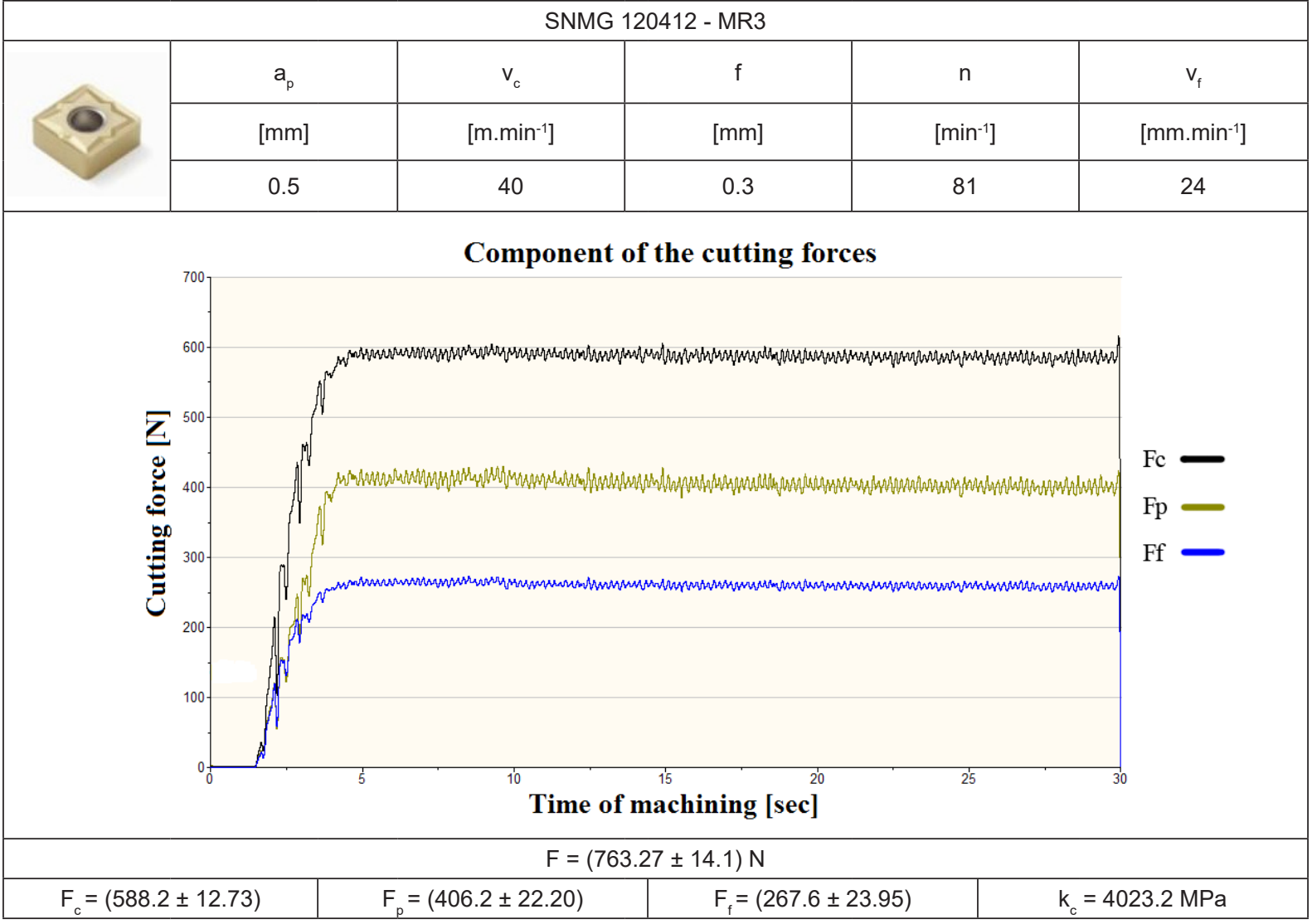

Table 4. The course of the force loading by a circular cutting insert $\left(a_{p}=0.5 \mathrm{~mm}\right)$

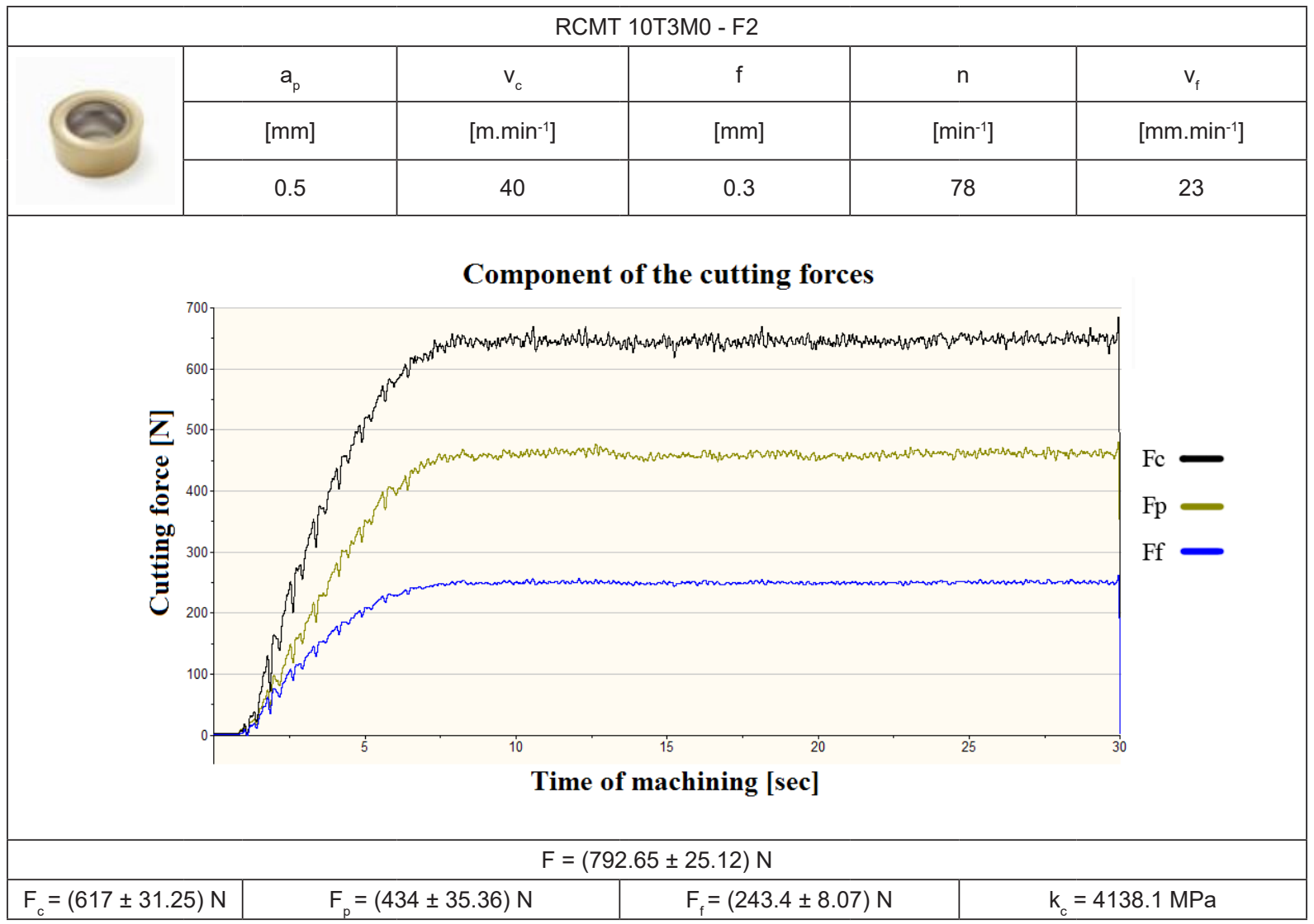


Table 5. The course of the force loading by a square cutting insert $\left(\mathrm{a}_{\mathrm{p}}=1.5 \mathrm{~mm}\right)$

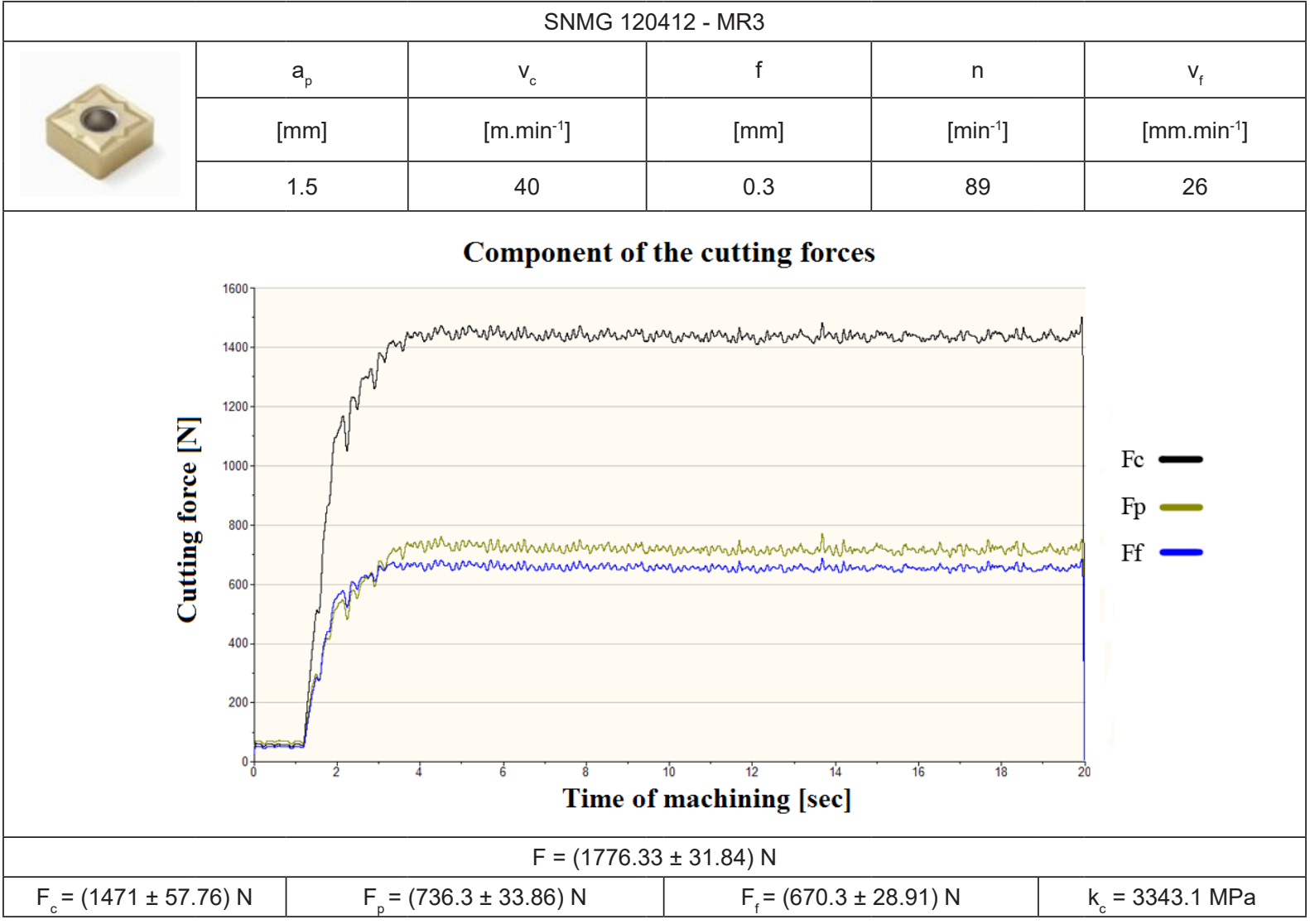

Table 6. The course of the force loading by a circular cutting insert $\left(\mathrm{a}_{\mathrm{p}}=1.5 \mathrm{~mm}\right)$

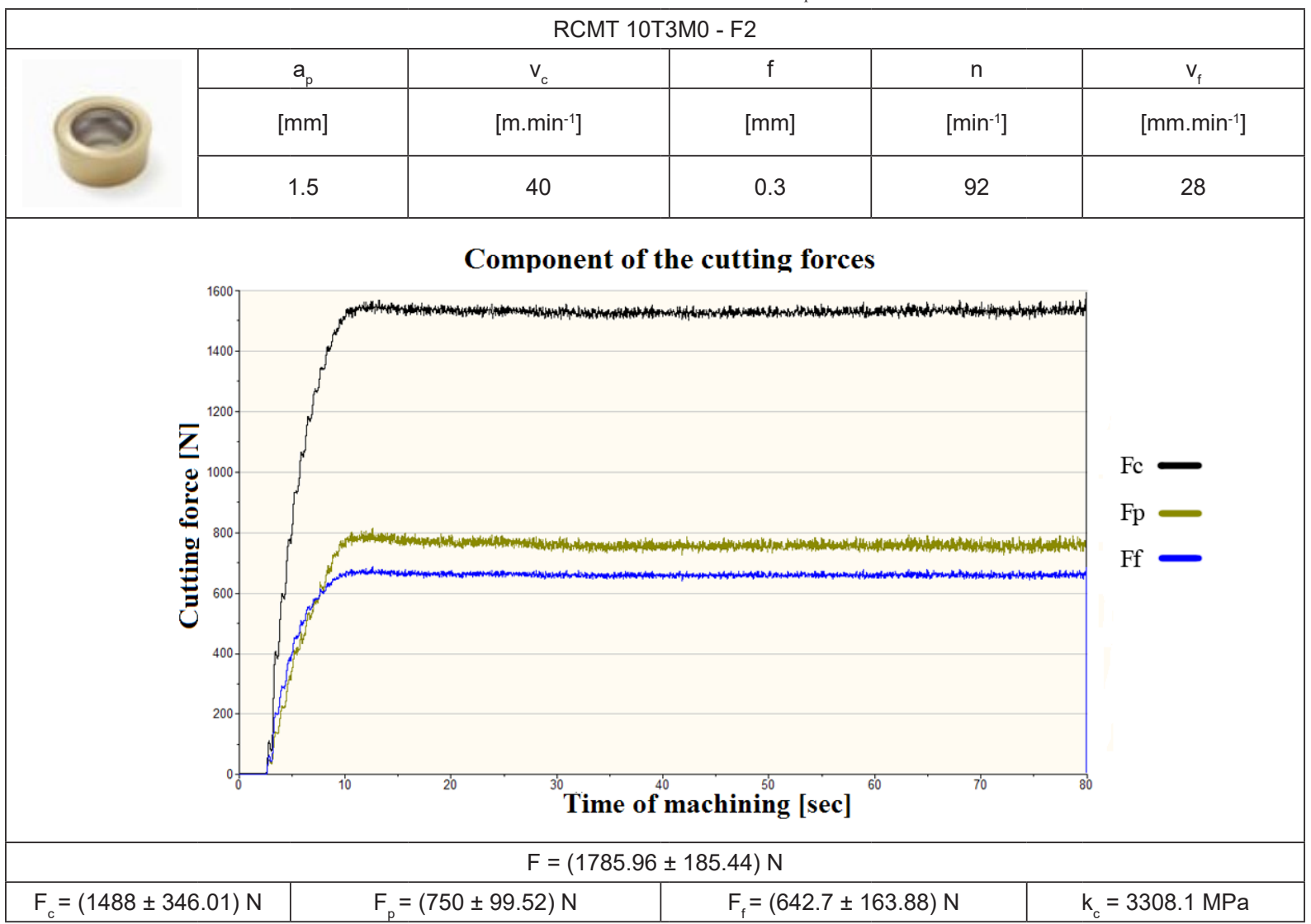




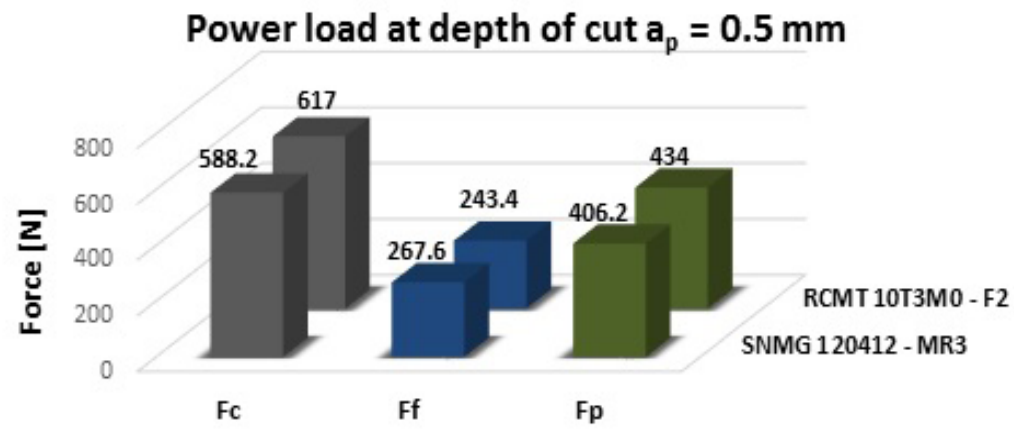

Fig. 4. Power load at depth of cut $a_{p}=0.5 \mathrm{~mm}$

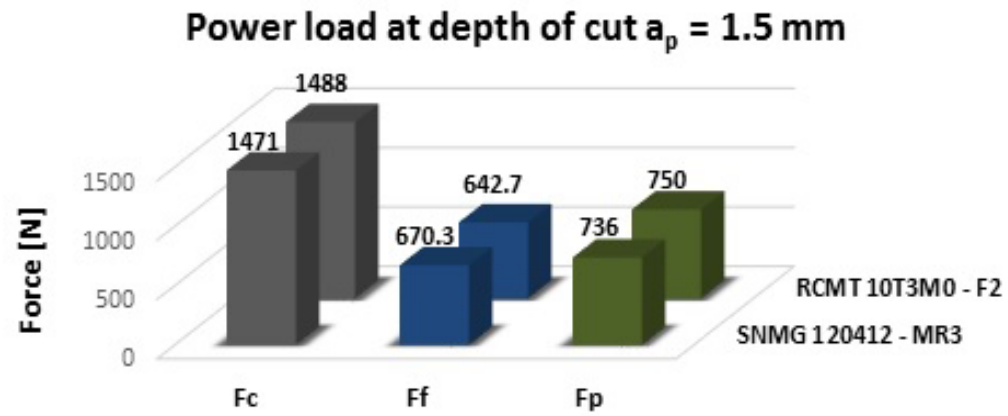

Fig. 5. Power load at depth of cut $\mathrm{a}_{\mathrm{p}}=1.5 \mathrm{~mm}$

ometry applied perpendicular force on the axis of the workpiece, straining the rigidity of the system and being the main prerequisite for the formation of deformation hardening of the material. The selected cut depth $a_{p}=1.5 \mathrm{~mm}$ resulted not only in the increase of all the cutting force components, but also in a change in their distribution. The course of loading clearly shows that there was not such a difference between the components $F_{p}$ and $F_{f}$ It can therefore be concluded that the entering angle $\kappa_{r}=45^{\circ}$ caused a uniform distribution of force action across the axial and radial direction of machining. The resultant of these two forces thus concentrated in the orthogonal direction and positively affected the entire machining process. A greater cut depth during the machining of Alloy 625 also resulted in a decrease of specific cutting resistance, which means a higher power load per area unit at a depth of cut of $a_{p}=2 \mathrm{~mm}$. The overall comparison of force conditions when machining Alloy 625 is shown in Figures 4 and 5.

\section{CONCLUSION AND EVALUATION}

Experimental machining of Alloy 625 (nickel alloy) was implemented in order to determine the effect of the geometry of cutting inserts on the course and magnitude of the dynamic load and stress acting on the entire machining system. The machining of materials such as nickel alloys is often problematic, mainly due to their low thermal conductivity, high strength at elevated temperatures, very hard abrasive particles contained in the material structure, inclination to intensive deformation hardening and other properties which affect the machinability of these materials [7, 14].

Decreased machinability of nickel alloys places higher demands on the selected machining technology, cutting tools and cutting conditions. However, by suitably adjusting the machining process, using a suitable tool, setting the appropriate cutting conditions and combining them, it is possible to achieve very good results in the machining of nickel alloys. In the process, emphasis is mainly on the required accuracy and quality of the manufactured components, the resulting state of the machined surface and on the economics of production, which, when machining materials such as nickel alloys, is largely affected by the durability of cutting tools as well as by using lower cutting conditions than when machining conventional steels. Therefore, the aim of cutting tool manufacturers and companies producing mechanical components and structures made of 
these materials is to find a suitable way to effectively machine these materials $[1,2]$.

One of the ways to avoid reduced life of the cutting tool when machining nickel alloys is to select a suitable cutting tool geometry. The main manifestation of wear on cutting tools is a notch on the rake and flank surface of the tool. This is due to low thermal conductivity, adhesion, as well as hardening of the surface layer material. Nickel alloys are very plastic materials prone to intense deformation hardening. The hardening is due to plastic deformation of the material, which causes deformation-induced martensitic transformation, which in turn leads to increased hardness. The material which has been hardened this way has significantly different mechanical properties than the base material; this causes intense wear of the cutting edge of the cutting tool, leading to defective quality of the machined surface and subsurface layers. A very intense surface hardening occurs due to the increased cut area between the cutting edge of the worn tool and the surface of the machined material which is being newly formed $[6,12]$.

During the experiment, the cutting inserts used involved those with different cutting edge geometry, namely circular cutting insert designated RCMT 10T3M0 - F2 and square cutting insert designated SNMG 120412 - MR3. The geometry of both cutting inserts met all the prerequisites for the machining of materials such as Alloy 625 (nickel alloy). Due to the assessment of the effect of cutting insert geometry on the dynamic system load when machining Alloy 625, two depths of cut $a p$ were selected. Depth of cut $a_{p}=0.5 \mathrm{~mm}$ and angle $\kappa_{r} \leq 45^{\circ}$ caused higher stress in radial direction of machining, and thus a greater difference between the cutting force components $F_{p}$ and $F_{f}$. Force acting in this direction exerted bending stress on the machined part and negatively affected the newly machined surface of the material (upsetting of the material, hardening of the surface layer, increase in the residual strains, formation of cracks, etc.). At depth of cut $a_{p}=1.5 \mathrm{~mm}$, the angle was $\kappa_{r}=45^{\circ}$ in both cases. This entering angle of the main edge distributed the loading cutting force components $F_{p}$ and $F_{f}$ uniformly over the entire length of the edge and prevented the maximum force load from acting in one direction only $[3,6]$.

Despite the different geometries of the two cutting inserts, the machining of Alloy 625 achieved very similar values of dynamic loading.
Except the feed component of the cutting force $F_{f}$ acting in the axial direction of machining, slightly higher loading values were achieved in the case of the circular cutting insert with positive cutting geometry than in the case of square cutting insert with negative cutting geometry. However, compared to the square cutting insert with a tip radius $r_{\varepsilon}=1.2 \mathrm{~mm}$, higher feed and hence higher machining efficiency can be achieved with a circular cutting insert, while keeping the required roughness of the machined surface.

\section{Acknowledgements}

This work was supported by the European Regional Development Fund in the IT4 Innovations Centre of Excellence project CZ.1.05/1.1.00/02.0070 and by Education for Competitiveness Operational Programme financed by Structural Founds of Europe Union in project Integrita CZ.1.07/2.3.00/20.0037 and by Student Grant Competitions SP2015/116 and SP2015/129 financed by the Ministry of Education, Youth and Sports and Faculty of Mechanical Engineering VŠB-Technical University of Ostrava.

\section{REFERENCES}

1. Neslušan M. and Czán A. Obrábanie titánových a niklových zliatin. Žilina, 2001.

2. Darecký J. Superzliatiny niklu a ich obrábanie. Žilina, Technical University of Žilina, 2001, 189.

3. Čep R., Janásek A., Čepová L., Petrů J., Hlavatý I., Car Z. and Hatala M. Experimental testing of exchangeable cutting inserts cutting ability. Tehnicki Vjesnik-Technical Gazette, 20(1), 2013, 21-26.

4. Bradley and Elihu F. Superalloys: A Technical Guide. ASM International, 1989, 280.

5. Maurotto A., et al. Comparing machinability of Ti15-3-3-3 and Ni-625 alloys in UAT. In 5th CIRP conference on High Performance Cutting, 2012.

6. Sandvik Coromant. Př́ručka obrábění. Praha: Scientia, s.r.o. Praha, 1997, 910.

7. Donachie M.J. and Donachie S.J. Superalloys - A Technical Guide, second edition. ASM International, 2002.

8. Stẹpień K.S. Testing the accuracy of surface roughness measurements carried out with a portable profilometer. Key Engineering Materials, 637, 2015, 69-73.

9. SECO TOOLS CZ, s.r.o. Soustružení, www.secotools.com. 
10. Venkatesan K., Ramanujam R., Saxena V., Chawdhury N. and Choudhary V. Influence of cutting parameters on dry machining of inconel 625 alloy with coated carbide insert - a statistical approach. In ARPN Journal of Engineering and Applied Sciences, 9(3), 2014, 250-258.

11. Petrů J., Zlámal T., Mrkvica I. and Čep R. The effect of thermal shocks on wear of exchangeable sintered carbide inserts during the cutting proces. Manufacturing Technology, 14(4), 2014. 590-596.

12. Petrů J., Schiffner J., Zlámal T., Sadílek M. and
Stančekova D. Investigation of cutting tool wear while machining inconel 718. Manufacturing Technology, 15(3), 2015, 396-403.

13. Duplák J., Hatala M., Botko F. and Kormoš M. Analysis of cutting tools durability importance in turning process of steel C60. In Key Engineering Materials, 669, 2016, 319-326.

14. Petrů J., Petřkovská L., Zlámal T. and Mrkvica I. Resistance of sintered carbide materials against heat shocks induced by cutting process. 23rd International Conference on Metallurgy and Materials, 2014, 973-978. 